\section{Long-term national databases}

SIR - Your article on North Sea data and "privatization" (Nature 361, 101; 1992) captures the general flavour of the debate although I would not wish to claim that all government departments of necessity take a short-term view, for many do not. However, in the case of the North Sea, the Department of Trade and Industry (DTI) appears to be taking (or is having to take) a short-term view of a long-term problem of curation of a major national geological database.

It is impossible to overstate the scientific and commercial value of the oil and gas database for the North Sea, which has cost billions of pounds to acquire and millions of pounds to curate. It will continue to be valuable long after oil exploration has ceased in the North Sea, just as geological data collected 150 or more years ago by the British Geological Survey (BGS) are still used. Other issues include the confidential access to the database, and the impartial advice that the survey can provide because of its status as a non-profit-making organization, but the crux of the issue is the quality and long-term continuity of the curation. Of course it will be claimed that contracts can be written to ensure that curation is undertaken to current BGS standards - just as new software commonly claims to be uniformly compatible! Of course companies will claim that they can provide a service that is just as good as that provided by the BGS and perhaps they will claim that they could provide long-term continuity of curation. But the fact is that the BGS has existed as the national survey for more than 150 years and I would expect it to do so for another 150 . How many geological companies have this track record or this future expectation? But this is the sort of timescale over which national datasets must be maintained and this is why I believe that the potential saving of a few pounds in 1993 is insufficient to justify jeopardizing the integrity of a dataset that will be consulted by geoscientists in 2093 or even 2193. Just as the United Kingdom environment must be sustained for the benefit of future generations, so must we also ensure the sustainability of the UK knowledge base for those following us.

The geological database for the North Sea, lodged with the DTI but obtained through the efforts of the oil and gas exploration industry over the past 25 years, can only be satisfactorily curated on a long-term basis by the BGS. In the national interest the data should remain with the British Geological Survey.

Peter J. Cook

British Geological Survey,

Kingsley Dunham Centre,

Keyworth, Nottingham NG12 5GG, UK

\section{Diet and cancer}

SIR - A recent leading article in Nature $(359,760 ; 1992)$ stated that further studies of the possible relation between fat consumption and breast cancer incidence are unwarranted in view of the negative results obtained in several case-control studies, notably the recent ones by Kushi and Willett.

We believe that this judgement is premature. Cross-cultural and migrational studies have provided evidence for a relationship between dietary fat intake and breast cancer, and that this effect requires a generation to become evident. This time lapse is in line with the apparent long latency of breast cancer and points to a major potential flaw in casecontrol studies. Such studies have the inherent limitation that they reflect current dietary patterns and become less accurate when recollections of past dietary habits are required. None of the cited case-control studies provided dependable data on fat intake before the age of 30 and thus did not address the issue of the dietary environment at puberty and shortly thereafter, a putative window for cancer initiation.

The role of incorporated body fat resulting from increased fat consumption is also ignored. It has been shown that increased body fat decreases oestradiol 2-hydroxylation resulting in decreased excretion of 2-hydroxyoestrone, but increases the formation of 16-hydroxylated metabolites; one of these, $16 \alpha$ hydroxyoestrone, has been shown to be genotoxic while no such effects were observed for 2-hydroxyoestrone. These changes can be detected in crossover studies in which large differences in fat intake are induced. Unlike these studies involving major alterations in fat consumption, in conventional case-control studies dealing with relatively small differences in fat intake the relationship between fat intake and breast cancer risk may not therefore be apparent.

We therefore suggest that the issue of the effect of fat intake on breast cancer needs to be assessed by properly designed epidemiological and biological studies that take into consideration the above interpretative pitfalls.

H. Leon Bradlow

Jack Fishman

Strang-Cornell Cancer

Research Laboratory,

510 East 73 Street,

New York, New York 10021, USA
Columbus a Jew?

SIR - The "Copernican" side of Columbus's enterprise (Nature 359, 564; 1992) seems to have been generally underestimated, if not ignored. But this link could open new perspectives on the origins of modern science.

Certainly, the "primitive skill in the measurement of longitude" displayed by Columbus cannot be simply accounted for as a purely practical ability. It rather suggests that Columbus may have known more about astronomy than the background of a simple mariner would have allowed him. Indeed, it seems likely that he benefited from the work of skilled Jewish astronomers and mathematicians, particularly his contemporaries Abraham Zacuto and José Vizinho. The members of the Jewish community, in their particular social condition, could pursue more unfettered scientific activity in such fields as astronomy and cartography, taking advantage of Arab discoveries and getting close to some of the subsequent Copernican views. Moreover, they were stimulated to make practical use of scientific knowledge, in response to the persecution to which they were subjected. The problem is then to establish in what circles some kind of new scientific ideas started to spread, with that obvious "prudence" that you rightly refer to.

A good case for the Jewish origin of Columbus himself has been made by Simon Wiesenthal in his very interesting book Operation Neue Welt - Judenverfolgung und Columbus-Reise (Laffont, Paris, 1972/1991). Curiously enough, this claim has been recently strengthened by the suggestion that Pope Innocent VIII (1484-92) may have had an important role in providing Columbus with more than financial support (Ruggero Marino, Cristoforo Colombo e il Papa tradito, Newton Compton, Rome, 1991). Innocent VIII was certainly from a Jewish family (his father was called Aharon Cybo), and he had close connections with Lorenzo de' Medici (which included financial enterprises too). It is possible to trace links between Copernicus and people connected in some way with Florence and the Medici family and between the same circle and the discovery of the New World.

By analysing in depth the cultural Jewish background of Columbus, and the international relations of the Jewish community, we may come to understand what would otherwise appear as a strange case of mysterious scientific clairvoyance.

\section{Umberto Bartoccl}

Dipartimento di Matematica,

Universita,

06100 Perugia,

Italy

NATURE • VOL 361 • 4 FEBRUARY 1993 